\title{
LA ENSEÑANZA DE LA HISTORIA LOCAL EN EL GRADO DE PRIMARIA CON MEMES: CÓRDOBA
}

Rafael Guerrero Elecalde ${ }^{1}$

Universidad de Córdoba

Miguel Jesús López Serrano²

Universidad de Córdoba

Recibido 30/10/2020 Aceptado 21/11/2020

\begin{abstract}
Este artículo tiene por objetivo dar a conocer los resultados de una investigación desarrollada en el Grado en Educación Primaria de la Universidad de Córdoba sobre el uso de los memes como recurso didáctico para la enseñanza de la historia local. La tarea consistió en la confección, por el alumnado, de diferentes memes relacionados con las biografías de personalidades del pasado de la ciudad para luego ser compartidos en el grupo privado de $\mathrm{Fa}$ cebook de la clase. Posteriormente, se les preguntó con un formulario de Google Forms, sobre los contenidos y el diseño de la docencia desarrollada, con el deseo de conocer si este tipo de herramientas son válidas para la formación de los futuros y futuras docentes de Educación Primaria.
\end{abstract}

5 This article aims to present the results of a research developed in the Degree in Primary Education at the University of Córdoba on the use of memes as a didactic resource for the teaching of local history. The task consisted in the creation, by the students, of different memes related to the biographies of personalities of the city's past, to later be shared in a private Facebook group. After, students were asked with a Google Forms form, so that they could reflect and express their opinions on the contents and design of the teaching developed. In this way, we propose to investigate whether these types of tools are valid in the training of future teachers of Primary Education.

\section{DOI}

https://doi.org/10.15366/didacticas2020.23.001

PALABRAS CLAVE

TIC; Didáctica de las Ciencias Sociales; Innovación pedagógica; Métodos de enseñanza. methods. 


\section{INTRODUCCIÓN}

Se hace imprescindible transitar nuevas vías que permitan perfeccionar la calidad de la enseñanza de las ciencias sociales, como la historia, ya que entre otras cuestiones son un elemento de primera magnitud para la formación de una ciudadanía crítica. Por eso mismo, en la educación superior, donde se lleva a cabo la preparación de los futuros y futuras docentes de Primaria, se hace necesario instaurar metodologías pedagógicas procedimentales, alejadas de las prácticas memorísticas, que animen al estudiantado a estimular el aprendizaje por medio de la indagación de información, la selección de fuentes, su interpretación y su análisis crítico (Gómez, Ortuño y Molina, 2014; Sáiz y Gómez, 2016; Santisteban, 2010; Domínguez, 2015).

En este caso, hemos querido desarrollar con el alumnado de la asignatura de Didáctica de las ciencias sociales, de tercero de Educación Primaria de la Universidad de Córdoba (España), durante el curso 2019/2020, una experiencia centrada en el aprendizaje de la historia local de la ciudad a través de la confección de memes.

La temporalidad forma parte de la cotidianeidad de las personas, estando presente en nuestro lenguaje, en experiencias o descripciones. Este concepto se va constituyendo durante toda nuestra vida, y es una función básica de la escuela el trabajarlo con los y las infantes para que sean capaces de manera continuada ir construyendo estructuras temporales cada vez más completas, complejas y abstractas. El alumnado necesita de un lenguaje temporal para poder explicarse y, a medida que vayan alcanzando un vocabulario más variado, será capaz de dotar de mayor significación sus relatos a la par que entender la realidad histórica en la que se desarrollaba. Estas son cuestiones que los docentes en formación deben valorar y la experiencia didáctica que se ha propuesto con el uso de memes como recurso didáctico puede ser un buen camino para que este concepto sea interiorizado por todos ellos y ellas.

Asimismo, una de las premisas que fundamentaron la planificación de esta experiencia fue evaluar la funcionalidad que tienen la elaboración y difusión de memes como recurso para el aprendizaje de contenidos de carácter histórico. Igualmente, se quiso comprobar el grado de motivación que muestra el alumnado por los conceptos históricos propios de la etapa educativa de Primaria cuando se utiliza en el aula un lenguaje actual con el que se sienten más familiarizadas, dejando de ser aburridos para ellos y ellas e incentivando así su curiosidad y las ganas de aprender. Con el objetivo de desechar esa idea que está imantada en el imaginario colectivo de que la historia es una disciplina con saberes muertos y poco prácticos en la vida diaria.

El estudio del medio es un método que, a nuestro juicio, es de gran valor para la docencia porque al estar íntimamente relacionado con el entorno cotidiano del estudianta-

1 Este artículo ha sido resultado de la investigación que se está llevando a cabo en el seno del Grupo “íNDICES. Investigación en Didáctica de las Ciencias Experimentales y Sociales" (SEJ-544), con sede en el Dpto. de Didácticas Específicas en la Facultad de Ciencias de las Educación, en la Universidad de Córdoba (España). 
do, es muy interesante para adquirir contenidos de historia, geografía y patrimonio (Clío 92, 1995: 22-27; Pedreño, 2015: 53). De este modo, los y las discentes se pueden instruir en la interpretación histórica, gracias a la curiosidad por la exploración lo que le es cercano, activando a su vez el interés por las ciencias sociales y su construcción (fig. 1).

Las diferentes disciplinas, y también la Educación, se han visto obligadas a transformarse exponencialmente al desarrollo de las TIC. De hecho, Internet ha provocado el surgimiento de nuevas competencias básicas para la sociedad en cuanto a las herramientas de la información y en métodos de enseñanza y aprendizaje (Prendes, 2007; Brünner, 2004).

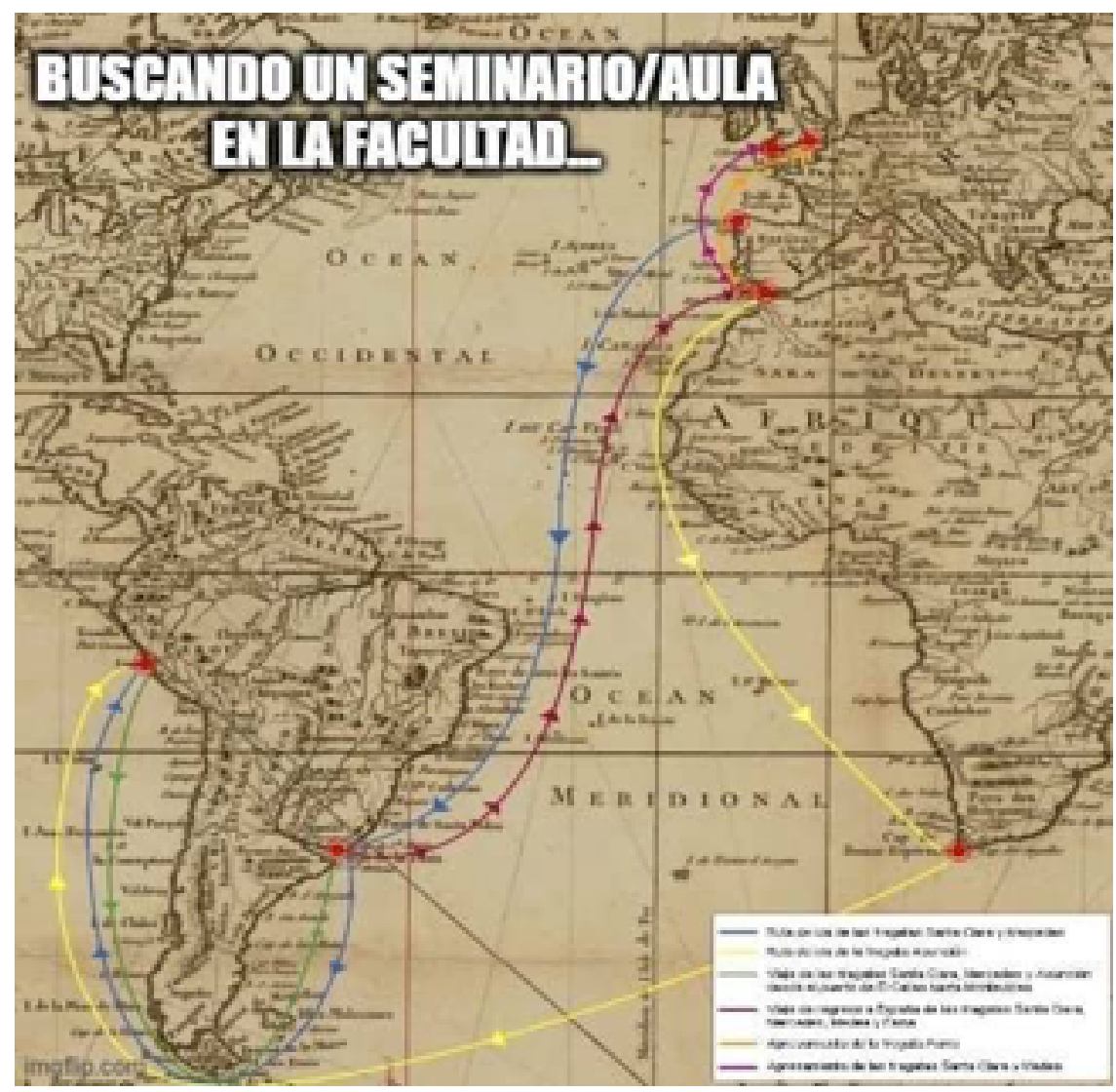

Fig. 1. Meme confeccionado por un alumno/a durante el desarrollo la actividad

Últimamente los espacios digitales están acaparando buena parte de las comunicaciones entre las personas y sociedades. En ellos, sin ninguna duda, los memes están de moda porque están inundando los dispositivos electrónicos, especialmente lo teléfonos móviles, a través de las diferentes redes sociales.

Con una apariencia sencilla por su formato y contenido, los memes encierran una importante complejidad en lo que respecta a su elaboración. Son elementos de pensamiento humano llenos de creatividad que exponen organizaciones de reflexión, que intenta co- 
nectar con el espectador a través del humor, tratando noticias actuales de la sociedad. Por eso mismo, estas imágenes, que están acompañadas por un sencillo texto, pueden ser un instrumento para formar el pensamiento crítico. Una gran ventaja para el y la docente es utilizar un lenguaje común y cotidiano entre el estudiantado, que entienden inmejorablemente, por lo que se podría explotar para ser usado como un recurso didáctico para el aprendizaje las ciencias sociales.

En definitiva, en este texto se transitará sobre una experiencia práctica docente desarrollada con alumnado en formación del Grado de Educación Primaria de la Universidad de Córdoba por medio de la utilización de recursos TIC, específicamente los memes, para la enseñanza o con aprendizaje de la historia local. Para esta práctica se ha decidido trabajar también en Facebook, que servirá como soporte para compartir entre los participantes sus elaboraciones y comentarios. A la hora de establecer el arco temporal de la práctica, ésta se articuló en torno a una serie de biografías de diferentes personalidades de Córdoba, que se repartieron de forma aleatoria entre el estudiantado, para que de este modo se concretaran los periodos históricos y, en definitiva, los resultados que se querían obtener.

Finalmente, una vez concluida la implementación de la actividad innovadora, se quiso conocer la opinión de los y las participantes sobre la experiencia didáctica realizada y de este modo reflexionar sobre los procesos de aprendizaje de la historia.

\section{MARCO TEÓRICO}

La historia local es un recurso de primer nivel para la interpretación de los hechos pasados (Prats, 1996). Las ventajas de su enseñanza y aprendizaje son abundantes y variadas, por lo que merece la pena abogar por su establecimiento en las aulas de Primaria, beneficiándose de las herramientas más novedosas y atrayentes para el alumnado. Los países anglosajones ya lo entendieron así y, en los años de 1950, fueron incorporando en el currículum de los distintos niveles educativos su estudio como pieza principal en los procesos de enseñanza de las ciencias sociales. Desde este prisma, otros países europeos siguieron esta línea, siendo uno de ellos España, principalmente desde la década de 1980 (Vázquez, 1987; Rogers, 1972).

Principalmente, es un recurso muy ventajoso para instituir un diálogo entre mundos diferentes que se encuentran interconectados como lo particular y lo general, los procesos locales con los comunes y lo concreto, conocido e inmediato con conceptos más complicados y abstractos. Y es que una interpretación compleja desde una perspectiva "local" es un primer paso para una reflexión hacia los orígenes de las estructuras y su devenir cotidiano (Pedreño, 2015). Así se colocan los resultados del aprendizaje en un marco más complejo, ya que el estudiantado entenderá que los conocimientos, las habilidades y las técnicas que están adquiriendo a través del estudio del medio son una parte esencial para comprender dinámicas amplias del pasado. La enseñanza de historia local puede otorgar 
una percepción general de la ocupación del territorio, de los recursos, así como de los problemas actuales, ya sean de índole económica, social, política, cultural o religiosa. De este modo, predominarán los contenidos que conllevan destrezas de reflexión más complejas (Prats, 1996).

También debemos tener en cuenta que el conocimiento del entorno facilita la construcción gradual de la identidad personal y proveen de habilidades para la intervención en el medio social y cultural (Clío 92, 1995; Aktekin, 2010; Pedreño, 2015), lo que favorece la vinculación de diferentes bloques temáticos de distintas áreas como la Historia, la Geografía, la educación para la Ciudadanía y la educación Técnica.

Es, por este motivo, que es recomendable la implantación de metodologías para la enseñanza de contenidos de ciencias sociales con el objetivo de estimular a descubrir y conocer el medio en el que desarrollan su vida y, de este modo, también reconociéndose con su entorno. Por este camino, poco a poco se irá alcanzando la complejidad intrínseca de la construcción de los procesos históricos (Gómez, Miralles, López y Prats, 2017).

Por último, la historia local permite descubrir las evidencias históricas de su espacio más próximo, que en muchas ocasiones se encuentran ocultas por la rutina cotidiana, aumentando su curiosidad por su entorno y su historia (Prats, 1996; Domínguez, 1986; Gómez y García, 2018). En este punto, se les puede ayudar para que adquieran competencias para introducirse en la interpretación histórica, con la incorporación de los conceptos teóricos apropiados y trabajando aspectos fundamentales en este campo como son el establecimiento de hipótesis, la comprobación y concreción del saber. La historia no debe ser para el alumnado una verdad acabada, o diferentes datos y interpretaciones que deben aprenderse de memoria, por lo que se hace indispensable que en clase se trabaje sobre ella incorporando toda su coherencia interna y ofreciendo las claves para acercarse a su estructura como conocimiento científico: entender cómo podemos conseguir saber lo que pasó y cómo debe ser explicado (Prats, 1996).

Entre otros, un buen método para adentrarlos/as en este campo es la elaboración de biografías de personajes que vivieron o influyeron poderosamente en el pasado de su entorno más cercano. De este modo, se podrá provocar la reflexión y el pensamiento crítico y los procesos de construcción individual y colectiva del conocimiento, ajustando un campo de observación concreto (Zepeda y Ezquerra, 2011).

Si la historia está construida gracias a la acción de hombres y mujeres, resulta interesante investigar y partir de sus biografías para la enseñanza de la historia. Por eso mismo, no se trata de una historieta descontextualizada, ni de un trabajo hagiográfico (ensalzar la vida de un "hijo ilustre"), sino la construcción del desarrollo de la vida de una persona en relación con la sociedad en la que vivió y a los acontecimientos sucedidos y que fueron determinantes a lo largo de su vida.

Se trataría de partir de la historia de agentes sociales e históricos con los que se comparten prácticas ordinarias de la vida cotidiana; partir de contenidos próximos al medio 
en el que vivimos permite crear espacios de identificación, proximidad y cercanía hacia la historia y sus actores. Además, esta es una buena manera para fomentar el pensamiento histórico, elemento primordial para la formación para una ciudadanía crítica, ya que el estudio de las sociedades del pasado provoca el razonamiento crítico junto con el análisis del mundo actual (Seixas, 2013; Seixas y Morton, 2013).

Sin embargo, los y las docentes de ciencias sociales nos encontramos con un problema cada vez más extendido: está disminuyendo poderosamente el interés por parte del alumnado de los temas relacionados con la historia porque entienden que corresponden a clases magistrales aburridas. Además, entiende que sus contenidos no son prácticos. Una de las causas de esta desmotivación puede que esté relacionada con el choque cultural que se está produciendo en las últimas décadas entre los y las discentes y equipos docentes, por lo que es necesario la implementación de una metodología innovadora y efectiva que afine este panorama (Vera, 2016).

En este sentido, las TIC brindan instrumentos muy ventajosos para el aprendizaje y es preciso beneficiarse de ellos. Actualmente, la información digital se está convirtiendo en un poderoso motor de cambio en la comunicación y el traspaso de conocimiento dentro de un mundo global (Denisova, 2019) y, para ello, Internet es la correa de transmisión. A través de cualquier dispositivo tecnológico, ya sea el teléfono móvil, ordenador o tableta y siempre y cuando tengamos conexión, se puede participar en un espacio creado virtualmente para facilitar la interacción entre personas (Herrera, 2012:123), siendo en los últimos tiempos los más destacados las redes sociales.

Un meme es una unidad básica de información digital que se transmite por medio de los diferentes medios virtuales. Se trata de una imagen, acompañada por un texto corto y original, cuyo objetivo es llegar a la mayor cantidad de audiencia posible. Su éxito estará garantizado si es óptima su capacidad expresiva para ser transmitido, si continua siendo identificable tras los procesos de traspaso, y está confeccionado para perdurar en el tiempo (Dawkins, 1976; Blackmore, 2000; Arango, 2015: 112).

En los últimos tiempos, los usuarios y las usuarias de Facebook, Instagram, Twitter o Whatsapp (entre muchas otras plataformas de este estilo) están consumiendo y compartiendo numerosas imágenes y vídeos con sentido humorístico, sarcástico o irónico como una nueva forma de expresión de denuncias sociales, manifestaciones políticas o de carácter caricaturesco, que se conocen como memes (Grundlingh, 2017; Huntington, 2016; Nissenbaum, y Shifman, 2017; Vélez, 2013).

Esta característica ayuda a que el meme se pueda expandir de tal manera, afectando directamente la cultura de las masas, ya que la risa constituye una conexión social en sí misma. Asimismo, muy relacionado con la exigencia del medio, los memes se replican o se extinguen siguiendo la ley de selección natural por la cual adquieren carácter viral, aunque el contexto de cada uno de ellos es primordial para comprender su significado (Pérez, 2017; Ross y Rivers, 2017). De este modo, se convierten en parte de la cultura po- 
pular en Internet y es en allí donde los usuarios y las usuarias le otorgan valor según su uso y masificación. La proliferación de foros, chats, webs y blogs ha conllevado la propagación y reapropiación de los mismos. En este sentido, la revolución del uso de los teléfonos móviles simplifica esa difusión masiva (Vélez, 2013).

Por lo general, nacen como una forma de interacción social, como referencias culturales o como una forma de describir situaciones de la vida real de las personas (Vera, 2017). Los contenidos y fines temáticos son variados, llegando a pasar traspasar lo humorístico, ya que podemos encontrar memes con intereses políticos, comerciales o de marketing, por ejemplo. Por eso mismo, pueden tener un interés didáctico y servir para transmitir conocimientos culturales, destacando especialmente el valor de la imagen en los procesos educativos (Vera Campillay, 2016).

La Educación, desde principios de este siglo, ha tenido que adaptarse y transformarse exponencialmente al desarrollo de las Tecnologías de la Información y la Comunicación (TIC). Respecto los memes y su uso para la enseñanza, queda mucho por hacer y sería de gran utilidad continuar investigando sobre esta relación, ya que puede llegar a ser una buena herramienta para la docencia debido a su popularidad entre el alumnado y su versatilidad: el aprendizaje se beneficia significativamente cuando se realiza a través de multitareas y procesos paralelos (Prensky, 2001) y el meme es un formato atractivo y comprensible según la realidad cotidiana del estudiantado; elementos que acarrean conocimientos culturales e ideológicos (Vera, 2017; Arango, 2014).

Los memes favorecen habilidades cognitivas como la memorización, incentiva la creatividad, refuerza la utilización de la síntesis, obliga a dominar los contenidos, capacita para el análisis y, por último, aviva la imaginación para construir y transmitir conocimiento. Por lo otro lado, propicia las búsquedas y selección de información, las habilidades digitales y la edición de contenidos y, por último, también es una fuente de información de la realidad, y por ello puede fomentar el pensamiento crítico, la creatividad y la curiosidad (Arango, 2015). Y es que se debe ser capaz de vincular los conocimientos adquiridos y elaborar una interpretación personal de la realidad con el desafío de comunicarla de forma humorística.

Por todo ello, debemos entender lo importante que es llevar a cabo una intensa alfabetización digital, que quede reducida a la educación mediática para el desarrollo de la competencia digital, entendida en su dimensión más tecnológica e instrumental (en los conocimientos técnicos, procedimientos de uso y manejo de dispositivos y programas), olvidando las actitudes y los valores.

Según la UNESCO, las cinco posibles competencias básicas en las que se centra la alfabetización mediática son: comprensión, pensamiento crítico, creatividad, consciencia intercultural y ciudadanía. Esto está relacionado con el desarrollo de los valores personales y sociales y de las responsabilidades derivadas del uso ético de la información (Gutié- 
rrez y Tyner, 2012). En definitiva, un uso de los recursos TIC de forma libre, digna y creativa.

El meme es un fenómeno de comunicación y cultural de gran magnitud que puede significar una herramienta didáctica muy valiosa con la que se puede cimentar nuevos conocimientos y conseguir competencias entre el estudiantado. Se trata de un vehículo muy efectivo en el proceso de enseñanza y aprendizaje, ya que el alumnado está muy habituado en manejarse en este campo con el conocimiento de los lenguajes y modismos específicos. El trabajo en el aula con memes permite transmitir un mensaje directo, claro y distintivo, a la vez que se muestra propicio para el aprendizaje cooperativo.

Ya se han llevado a cabo algunos trabajos de investigación sobre estas cuestiones, utilizando el meme como recurso para el aprendizaje de matemáticas (Beltrán Pellicer, 2016) y el lenguaje y comunicación, por ejemplo, y en las páginas siguientes vamos a presentar una experiencia de una práctica docente para el aprendizaje de las ciencias sociales, más concretamente de la historia.

\section{DISEÑO DE LA INNOVACIÓN DOCENTE Y METODOLOGÍA}

Desde estos argumentos, en el curso 2019/2020, se estableció una innovación con el alumnado de tercer curso del grado en Educación Primaria de la Universidad de Córdoba para dar a conocer y estudiar la historia local. Para ello, y para conseguirlo de la manera más interactiva, activa y lúdica posible, se decidió trabajar con recursos TIC, siendo la herramienta principal los memes.

El proceso metodológico que propusimos implantar para esta actividad, para construir un aprendizaje significativo, se caracterizó por ser flexible y participativo, con la intención de reincidir en la comparativa histórica. Se planteó la actividad como un trabajo individual, fundamentado en una tarea anterior de carácter grupal, en la que cada equipo estuvo conformado entre 5 y 6 personas, constituyéndose un total de 13 grupos, que estuvo dedicado a la búsqueda, selección y publicación de información de biografías de diferentes personajes estrechamente relacionados con la historia de Córdoba.

Cabe destacar que la selección no se centró específicamente en las personalidades más conocidas de la historia de Córdoba, sino que se prefirió tener en cuenta otros criterios en su elección, como la variedad cronológica (hay personajes desde la antigüedad hasta el siglo XX), tener en cuenta diferentes profesiones, estados y campos de actuación y la ponderación de acción de las mujeres en la construcción de la historia, huyendo de este modo de las construcciones más tradicionales (véase fig. 2).

Por lo tanto, se trató de una práctica individual en la que cada alumno y alumna debió diseñar como mínimo dos memes de creación propia (aunque no se estableció un límite), relacionados con las biografías anteriormente trabajadas sobre la historia de Córdoba. 

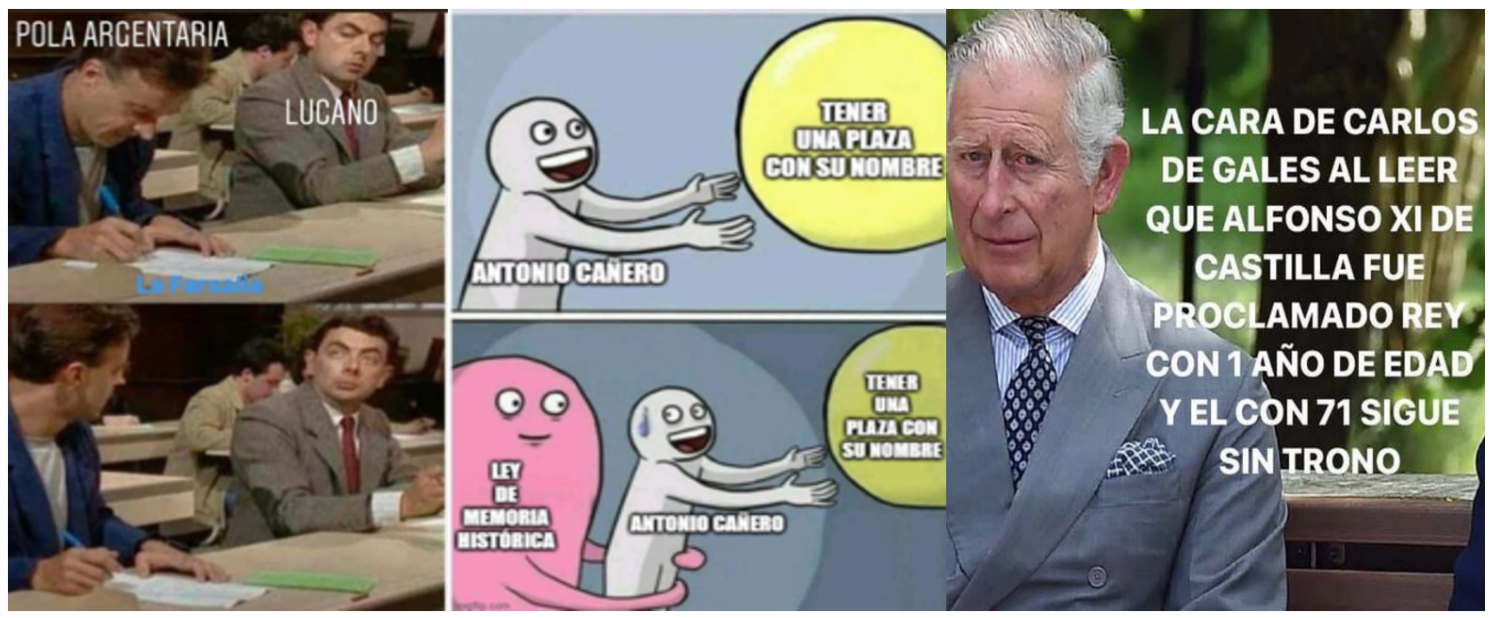

Fig.2. Memes confeccionados por alumnos/as durante el desarrollo de la actividad.

Pero, ¿cómo se hace un meme para enseñar historia?

Paso 1. Investigar un tema para elegir el momento histórico que quieres representar.

Paso 2. Comprender muy bien la teoría para poder estructurarlo coherentemente.

Paso 3. Hacer un análisis crítico del contenido que ayude a seleccionar las ideas principales, eligiendo las que le son útiles y descartando las que no.

Paso 4. Seleccionar una imagen que se acomode al mensaje que se quiere emitir.

Paso 5. Agregar el texto a dicha imagen: Tendrá que ser sencillo, breve y principalmente divertido y atractivo. En su disposición, se estudiará las composiciones de color, el lugar dentro de la imagen y el tamaño.

Paso 6. Publicarlo en las redes sociales.

Existen numerosas y variadas aplicaciones para el móvil y páginas web que se pueden encontrar en Internet, pero para aquellos estudiantes menos avezados se les propuso que utilizaran la app Mematic, cuya web es https://www.mematic.net.

Como los memes hay que compartirlos, se decidió utilizar Facebook para ello. Se hizo en dicha plataforma un grupo cerrado para este fin, donde solo el profesorado era el administrador/a. Técnicamente, es sencillo y además todos ellos tienen cuenta en esa u otras redes sociales pertenecientes al propietario/a de dicha empresa, por lo que los problemas que pudiera acarrear la privacidad de los datos personales quedaron resueltos.

Además, el alumnado debió acompañar la publicación de su meme un comentario explicativo y con carácter educativo: personaje, hecho concreto al que se refiere... para ayudar a comprender mejor su creación y para favorecer la interacción del resto de sus compañeros. 
En este sentido, era obligatorio participar del resto de los post dando "me gusta" a los memes que más les haya gustado o llamado la atención hasta un máximo de cinco. Los criterios que debía utilizar para ello debían ser la originalidad y creatividad, su validez para ser usados como recursos didácticos y que estén ajustados a los contenidos trabajados de historia local. Para incentivar la motivación del profesorado en formación por esta actividad, se les comunicó que se iba a anunciar en el muro del grupo de Facebook los cinco memes que habían tenido más éxito entre la clase.

\section{Cronograma de la actividad}

La actividad estuvo planificada con una metodología para ser desarrollada completamente online, como consecuencia del confinamiento que en España se decretó a lo largo del año 2020 por la COVID-19. Por este motivo, se establecieron dos sesiones de trabajo, de hora y media cada una y a través de videoconferencia, al principio y al final de la tarea, a la vez que los alumnos y alumnas tenía la libertad de entrar en el grupo privado de Facebook de clase para participar activamente y en colaboración con el resto de los compañeros y las compañeras. La duración del trabajo de curso estuvo planificada para una semana y a lo largo de la misma, también por videoconferencia se establecieron dos pequeñas reuniones de 10-15 minutos dirigidas al seguimiento de la actividad.

\section{Sesión 1}

Se concretaron los grupos de trabajo (de 4 o 5 personas) y se realizó a la presentación de la práctica, explicando que se trataba de una actividad individual, en la que se debía interactuar con el resto de compañeros y compañeras. De manera concreta, a lo largo de la primera sesión, se presentó el grupo privado de Facebook de la clase, para que el alumnado comenzara a solicitar su incorporación como miembro, así como se realizó el reparto de las biografías relacionadas con la historia de Córdoba a los equipos de trabajo, de las cuales deberían elaborar los memes.

Sesiones 2 y 3

En estas reuniones, de un tiempo mucho más corto de duración, se dedicaron a realizar una puesta en común para compartir dudas, sugerencias e información, con el interés de que fuera útil a la hora de la conclusión final de la labor.

\section{Sesión 4}

Tras la publicación de los memes elaborados por el estudiantado, se realizó una puesta común final sobre la tarea con el objetivo de llevar al alumnado a reflexionar sobre lo aprendido. 


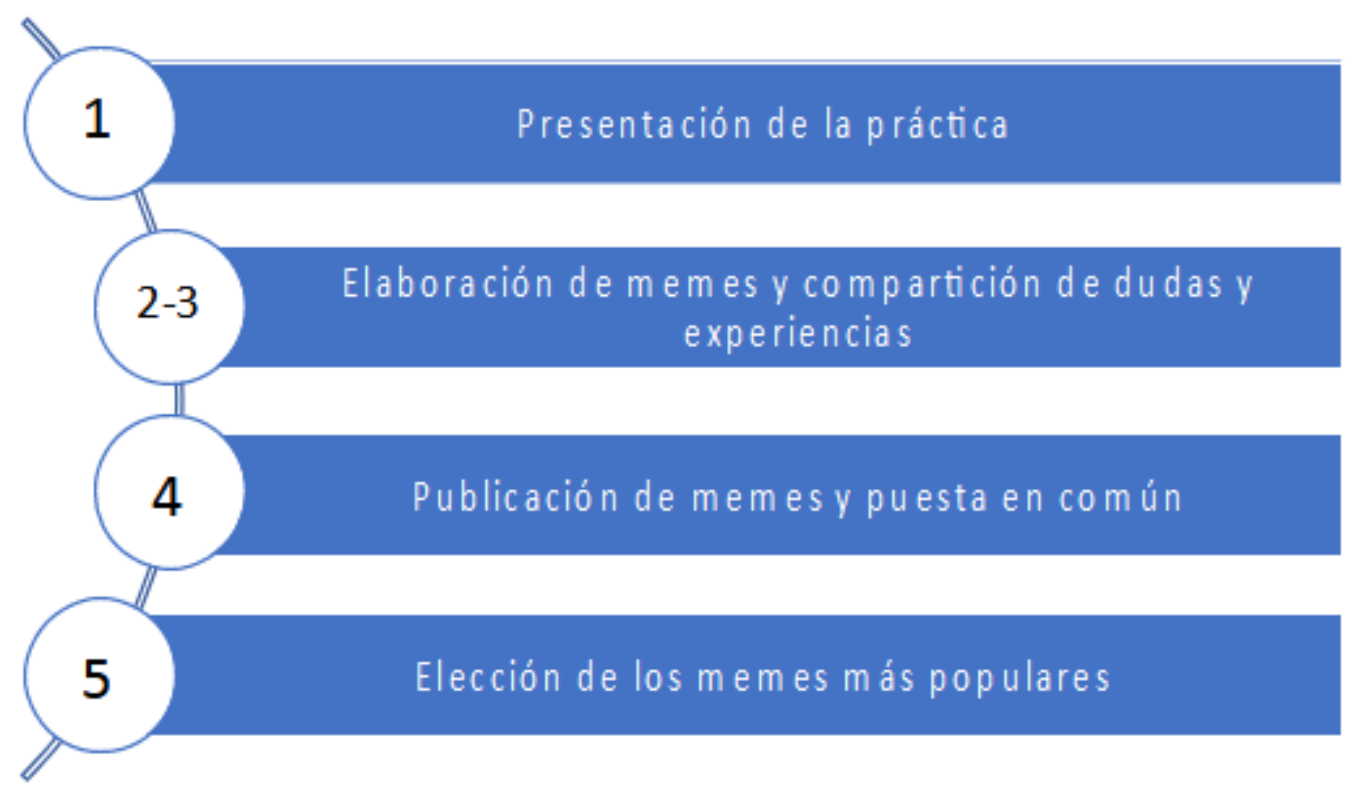

Fig. 3. Secuenciación de actividades. Elaboración propia.

Se terminó la actividad con la elaboración de la lista con los cinco memes más comentados y con más "me gusta" de los confeccionados, compartiéndolos a la vez en el muro del grupo.

\section{Metodología}

Una vez que estuvieron bien determinadas y constituidas las etapas de la práctica, se formularon una serie de objetivos generales y específicos:

Objetivos Generales:

- Ejecutar estrategias metodológicas que pongan en valor la enseñanza de la historia local en Educación Primaria.

- Conocer la percepción de los futuros maestros y maestras sobre el trabajo con recursos TIC (memes y redes sociales) en lo que respecta a la mejora de la calidad de la enseñanza de contenidos de ciencias sociales.

- Desechar la idea de que la historia es una disciplina estática y poco práctica para la vida diaria.

Objetivos específicos:

- Valorar el comportamiento del estudiantado utilizando recursos TIC (memes y redes sociales) como elemento transmisor de contenidos de las ciencias sociales. 
- Estimar el progreso o no del desarrollo de la conciencia histórica a través del trabajo con recursos TIC (memes y redes sociales)

- Valuar el interés del uso de recursos TIC (memes y redes sociales) en su labor como futuros y futuras docentes.

- Fomentar la comparativa pasado- presente mediante la utilización de recursos TIC (memes y redes sociales). Identificar características textuales para la elaboración de meme a partir de la biografía seleccionada.

- Hacer entender a los y las docentes en formación de la importancia de la construcción del lenguaje temporal para el alumnado de Educación Primaria.

\section{Participantes e instrumentos de análisis}

La investigación se realizó sobre una muestra potencial de 65 matriculados en la asignatura de Didáctica de las Ciencias Sociales, contando con una participación total de 58 personas ( $\mathrm{n}=58$ ); un $87,7 \%$ del alumnado matriculado, donde el $62,1 \%$ eran mujeres y el $37,9 \%$, hombres. Entre ellos, el 43,1\% del total tiene su lugar de residencia habitual en la ciudad de Córdoba, mientras que el resto lo hacen en el resto de la provincia.

Posteriormente a la actividad, se preguntó al alumnado a través de un formulario de Google Forms sobre sus impresiones y perspectivas acerca de los contenidos y el diseño de la docencia de las ciencias sociales. Este cuestionario se compuso por un total de 38 preguntas, no validado por expertos, con preguntas de carácter abierto y cerrado. El examen de las respuestas adquiridas facilitó formalizar evaluaciones tanto de corte cuantitativo como cualitativo acerca de las competencias desarrolladas a través de la tarea y su apreciación sobre lo conveniente de la utilización de la prensa histórica para el aprendizaje de la historia local. Para el análisis de la información conseguida se usó el paquete estadístico SPSS, versión 25.0 para Windows.

\section{RESULTADOS}

En general, la inmensa mayoría del alumnado encuestado reaccionó positivamente ante la innovación educativa propuesta con los memes. Entre los encuestados y encuestadas, el 75,9\% (44) se mostraron completamente interesados con esta actividad, el 19\% (11) dijo que estaba de muy interesado. El resto, 5,2\% (3), estuvieron de interesados.

Los argumentos son diversos, pero los más recurrentes tienen que ver con el uso de recursos TIC (alumno/a 1, 3, 8, 11, 16, 17, 21, 29, 32, 35, 36, 37, 39, 41, 50, 52), y con el estudio de su entorno más cercano (alumno/a 1, 5, 9, 11, 14, 19, 26, 27, 29, 38, 43, 46, 49, $51,54,55,57)$. A la vez, el estudiantado mostró su sorpresa por aprender con estos recursos (alumno/a 9, 12, 29, 30, 31, 33, 34, 39, 44, 54), a la vez que se incentiva su motivación (alumno/a 5, 10, 17, 42, 55, 57) a la hora de afrontarla porque les pareció, principalmente, 
divertida (alumno/a 10, 11, 12, 13, 15, 19, 20, 23, 25, 26, 27, 28, 32, 35, 37, 38, 40, 41, 43, $46,47,48,50,51,52)$ : "hemos estado motivados y muy entusiasmados" (alumno/a 12).

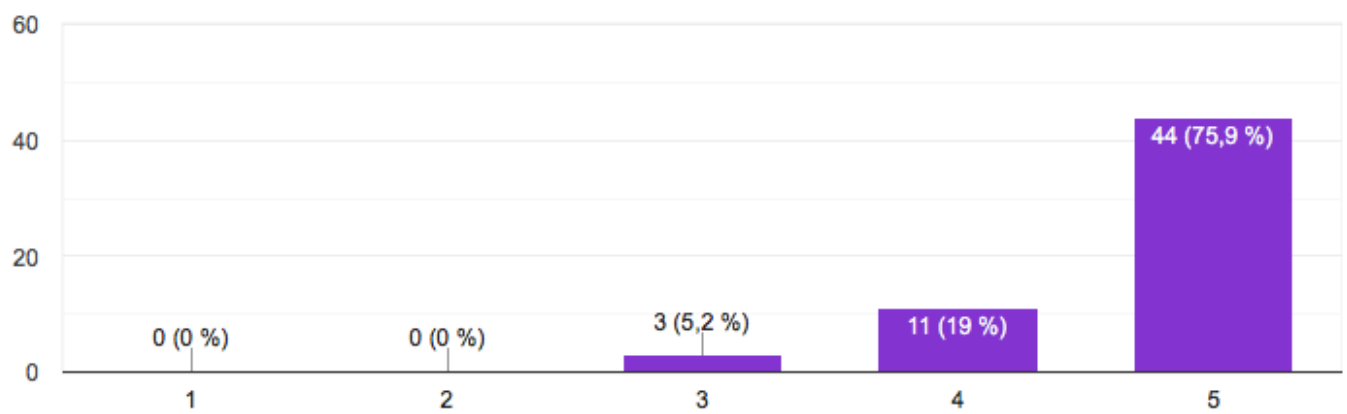

Fig. 4. ¿Te ha parecido interesante y educativa la actividad? Elaboración propia.

También se preguntó si a lo largo de su vida académica habían trabajado con ambas herramientas para aprender contenidos de las ciencias sociales y la historia local, a lo que respondieron negativamente en su mayoría: un $81 \%$ sobre las redes sociales y un 79,3 en lo que respecta a las biografías.
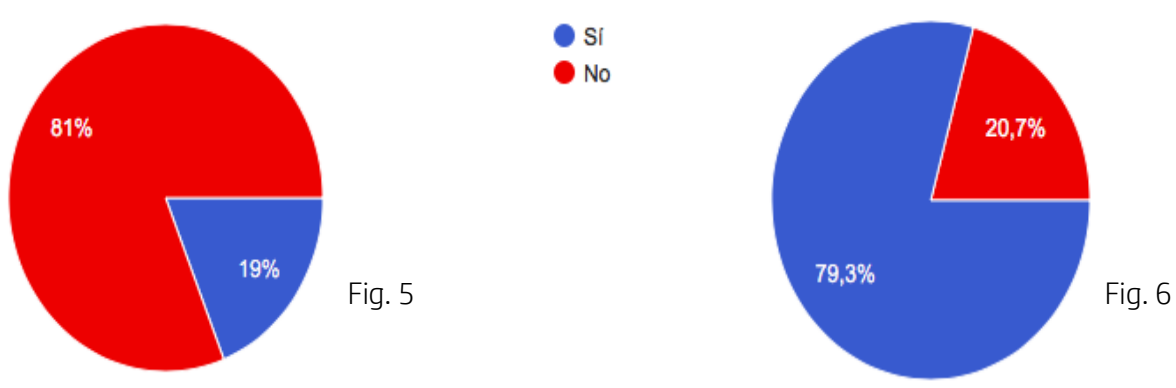

Fig. 5. ¿Habías trabajado con alguna red social como recurso didáctico? Elaboración propia.

Fig. 6. Como alumno/a, ¿has trabajado alguna vez con biografías? Elaboración propia.

Y en aquello y aquellas que trabajaron alguna vez con estas últimas, su experiencia no fue del todo satisfactoria, tal y como contemplamos en sus explicaciones. Así, por ejemplo, el alumno/a 1 comentó que "he trabajado con biografías pero fue de una manera más pesada y era copiar y pegar la información de una persona vi que de esa manera poco se aprendía, en cambio de esta nueva manera he aprendido bastante y de una forma más divertida" o el alumno/a 26, "he trabajado con biografías pero fue de una manera más pesada y era copiar y pegar la información de una persona vi que de esa manera poco se 
aprendía, en cambio de esta nueva manera he aprendido bastante y de una forma más divertida”.

Sin embargo, y gracias también al trabajo con memes, el alumnado comprendió en su mayoría que ha mejorado su capacidad de entender la historia de su ciudad: el 62,1\% (36), por supuesto; 24,1\%, muy evidentemente; y el 8,6\% (5), de acuerdo. Solamente, el $3,4 \%$ (2) y el $1,7 \%$ (1) estuvieron poco y nada conformes con ello.

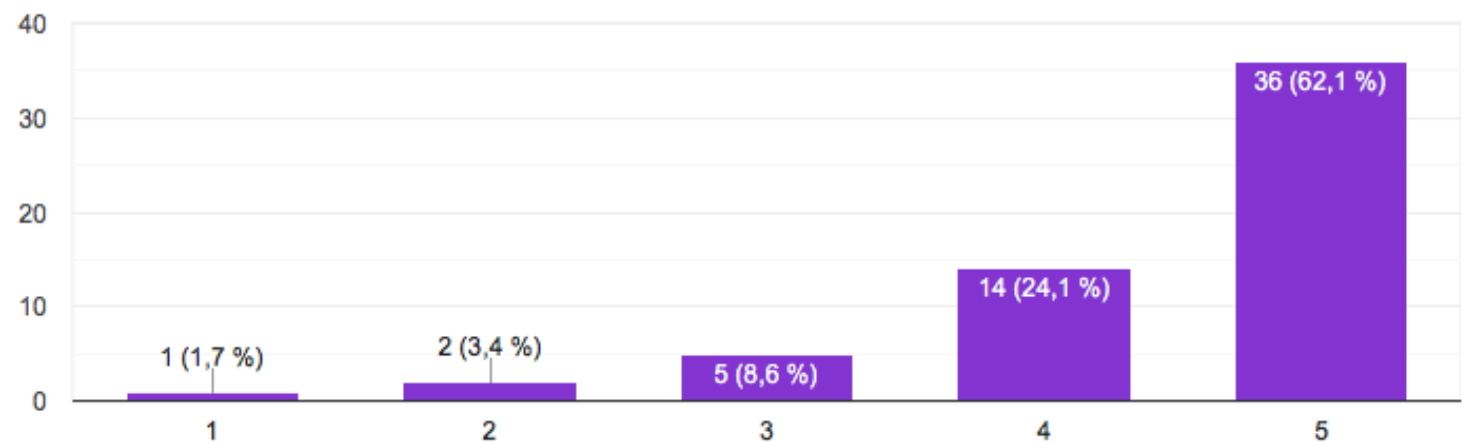

Fig. 7. Ha mejorado tu capacidad de pensar la historia de tu ciudad a través de esta práctica con memes. Elaboración propia.

De este modo lo explicó el alumno/a 10: "Porque, aunque el resultado de este sea sencillo, el proceso de elaboración es complejo, ya que requiere una serie de fases, las cuales son: en primer lugar, investigar exhaustivamente la vida de un/a personaje para conocerlo/a a la perfección; en segundo lugar hay que detectar algún rasgo característico de su personalidad o acontecimiento relevante, en el que haya participado; posteriormente es necesario desarrollar la creatividad para elegir las palabras adecuadas, la imagen, etc. Todo ello, te proporciona un gran conocimiento de la historia”.

Y el alumno/a 23: "Que al querer realizar los mejores memes investigas mucho más sin darte cuenta, para que el tuyo sea el más inteligente y divertido que el de tus compañeros/as; y para ello hay que analizar la Historia”.

Este es uno de los aspectos que los participantes resaltan: la investigación previa que se necesita para la realización de un buen meme (alumno/a 22, 23, 36, 39, 44, 48, 50, 52, 57): completamente de conforme, el 69\% (40); muy de satisfactorio, el 27,6\% (16) y de acuerdo, el 1,7\% (1).

Por otro lado, los y las estudiantes comprendieron que los memes pueden ser un buen soporte para el aprendizaje tanto de la historia local como de la Historia, en general, estando completamente de acuerdo el 67,2\% (39) y el 63,8\% (37), respectivamente.

Por este motivo, el 91,4\% (53) concibió que había aumentando su capacidad de pensar la historia local gracias a la práctica realizada. Hay que tener en cuenta que esta percepción deriva tras un trabajo que posee unas características muy concretas (una muestra 
pequeña, un tema que se circunscribe a un ámbito geo-histórico delimitado como la ciudad de Córdoba...), por lo que se deben tomar como un punto de partida para próximos trabajos. Por eso, un complemento interesante de la investigación ha sido recabar las percepciones del alumnado a este respecto.

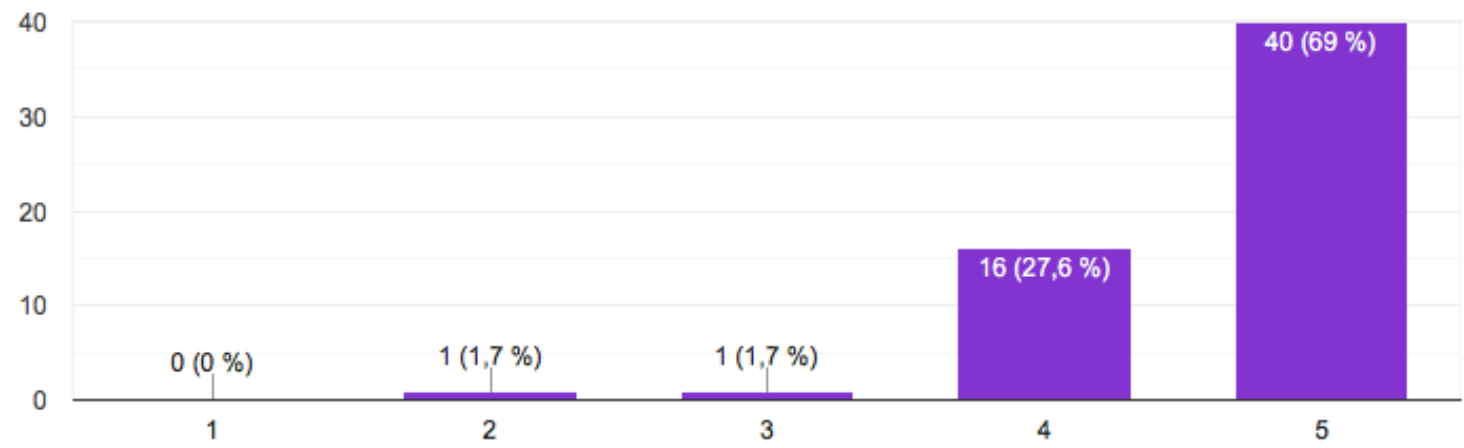

Fig. 8. Trabajar con memes puede fomentar la investigación histórica. Elaboración propia.

En este aspecto, el alumnado respondió de forma diferente, ya fuera como creador/a de los memes o como receptor/a de los que realizaron sus compañeros y compañeras. Desde la perspectiva del autor o autora, "para realizarlos tienes que informarte bien y analizar muchos aspectos sobre la vida y los acontecimientos de los personajes para poder realizar humor" (alumno/a 9) (véase fig. 9). Además, ha habido que basarse "en fuentes fiables, para conseguir el mejor resultado posible" (alumno/a 12) y así "comprender a los personajes, teniendo en cuenta el contexto histórico en el que se encuentran y sus ambiciones, pudiendo analizar las acciones que se llevaron a cabo para lograr su objetivo" (alumno/a 57).

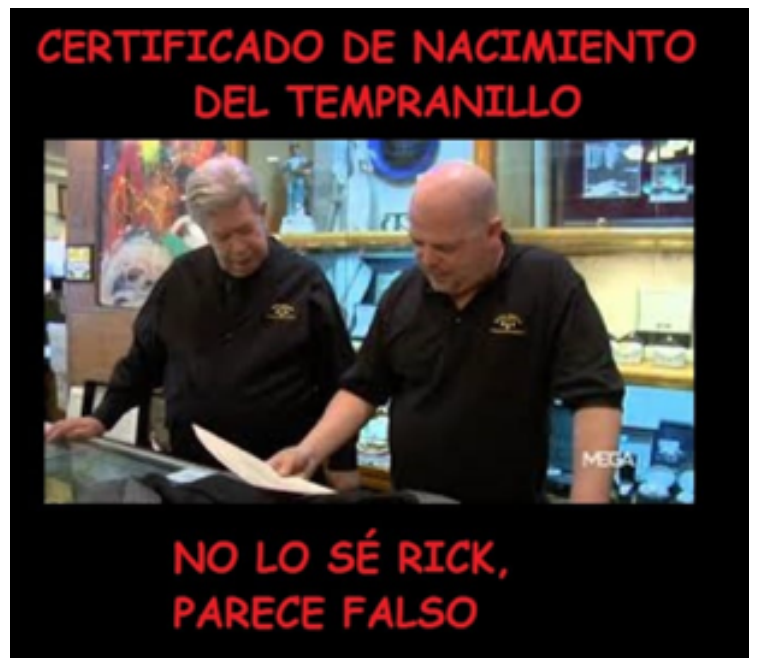

Fig. 9. Meme confeccionado por un alumno/a sobre el bandolero cordobés El Tempranillo. 
Por su parte, como espectador/a, aunque "el pensamiento histórico se produce a través de la reflexión, y mediante los memes puedes llegar a ese tipo de reflexión, pero no de una forma que permita conocer en profundidad la historia, más bien, destacar acontecimientos importantes, o algún momento relevante de la vida de personajes históricos" (alumno/a 16). Por eso mismo, "se trata de un recurso que debe ser complementario de otros donde se difunda una información más precisa" (alumno/a 42) y "aunque en realidad puede despertar el interés del alumnado en cuestión y hacer que busquen más sobre dicho tema, normalmente no es asî" (alumno/a 47).

Cuando les planteamos que abiertamente expusieran qué les ha parecido la actividad, la mayoría de los encuestados y encuestadas se mostraron satisfechos y satisfechas tras la actividad y reconocieron que, tras una apariencia de sencillez o de simpleza, la elaboración o la interpretación de un meme de carácter histórico requiere trabajo y conocimiento:

"Parece una práctica fácil, pero no lo es. Me llevó mi tiempo porque no soy una persona muy imaginativa en ese aspecto, pero he conseguido hacer dos buenos memes que los podría utilizar en primaria sin ningún temor (...). Tampoco puedo obviar, que me he reído bastante con los memes de mis compañeros porque algunos son muy buenos. Es una manera distinta de aprender historia y que sin duda me llevo una gran experiencia no solo de esta, sino también de las anteriores" (alumno/a 2).

Igualmente, "a primera vista parecía una práctica muy sencilla, pero que esconde un gran trabajo detrás, ya que debes conocer bien a los personajes, cuándo, dónde y cómo se desenvolvían, para después pensar en algo gracioso para hacer un meme. Además, al leer las aportaciones del resto de compañeros/as te diviertes y descubres cosas que desconocías”. (alumno/a 9).

Por último, "lo que más me ha llamado la atención es que al principio puedes pensar que no es un método con el que aprender historia, pero una vez te metes en la actividad, y la llevas a cabo, ves que sí y que además de aprender sobre la historia de tu ciudad, de personajes, etc., se convierte en una actividad muy divertida y puedes pasarlo bien tanto fabricando los memes como leyendo los de los demás" (alumno/a 5).

\section{DISCUSIÓN}

La mayoría del alumnado del Grado de Primaria entendió como positiva la innovación, lo que nos confirma que se debe introducir herramientas innovadoras de enseñanza en las aulas universitarias, que estén dirigidas a la implantación de metodologías activas de aprendizaje de contenidos sociales en las etapas educativas obligatorias. Lo primordial es que el profesorado acomode los contenidos para que sean inteligibles y de fácil acceso para el alumnado. 
Si tenemos en cuenta las respuestas de los encuestados/as, la programación de la actividad, fundamentada en el trabajo de la historia local y la explotación de herramientas diferentes a las tradicionales como son las TIC, fue un acierto. Según expresaron, el aprendizaje del entorno (de lo más cercano) les ha concedido un enriquecimiento personal y unos conocimientos que han expresado les han sido muy valiosos para su futura labor como docentes (Prats, 1996).

Por lo tanto, el meme se ha mostrado como una herramienta de gran valor para la didáctica de las ciencias sociales, ya que a partir de su confección y de su lectura se pueden convertir en fuentes de información que pueden ser aprovechadas potencialmente como herramienta didáctica en la enseñanza de la Historia. Igualmente, ayuda al desarrollo de las habilidades para conseguirlo. El meme también es un espacio donde se entrecruzan la enseñanza y la cultura popular actual, en cuanto permite conectar la vida social de los adolescentes y los contenidos específicos académicos (Scardina, 2017).

Por otro lado, como herramienta, posibilita hacer y diseñar conocimiento en su proceso de aprendizaje y, de acuerdo a esta construcción el estudiantado puede dar un sentido a lo que aprenden. Por eso mismo, el meme admite mostrar contenidos procedimentales o ayudar al entendimiento de relaciones funcionales y causales complejas, en cuanto a diversos (Vera, 2019), también en las ciencias sociales.

Sin embargo, no debe ser el utensilio opcional en este proceso de enseñanza-aprendizaje de la historia, sino que tiene que ser un recurso adicional. Por una parte, se puede utilizar como actividades de introducción o iniciales, que sirvan para incentivar la curiosidad y motivar al alumnado hacia los contenidos que se van a tratar, así como para realizar una evaluación inicial y de este modo conocer los conocimientos previos de la clase sobre los temas que se van a trabajar en la unidad didáctica. Así, por ejemplo, el y la docente puede presentar unos memes que ha elaborado anteriormente para que el estudiantado comience a preguntarse por la información que encierra. Por su parte, y desde otra perspectiva, se pueden planificar tareas de síntesis-resumen, de consolidación y de ampliación-profundización para que el alumnado elabore memes en relación con los contenidos que han aprendido tras el fin del tema según el objetivo que queramos conseguir como docentes.

Este método de trabajo fue también una manera de fomentar el trabajo colaborativo, situando al estudiante en el centro del aprendizaje y favorece la educación en valores porque provoca el respeto y la aceptación, la empatía y la autoestima o la ayuda mutua y la solidaridad. Igualmente, se construye un sentido de pertenencia (tanto con el grupo como con la clase) y una interrelación positiva originada del compromiso por conseguir los objetivos individuales y comunes. En este punto, las nuevas tecnologías y las redes sociales se han convertido en un catalizador para el trabajo cooperativo, donde se establece una comunicación a cualquier hora y en cualquier lugar. 


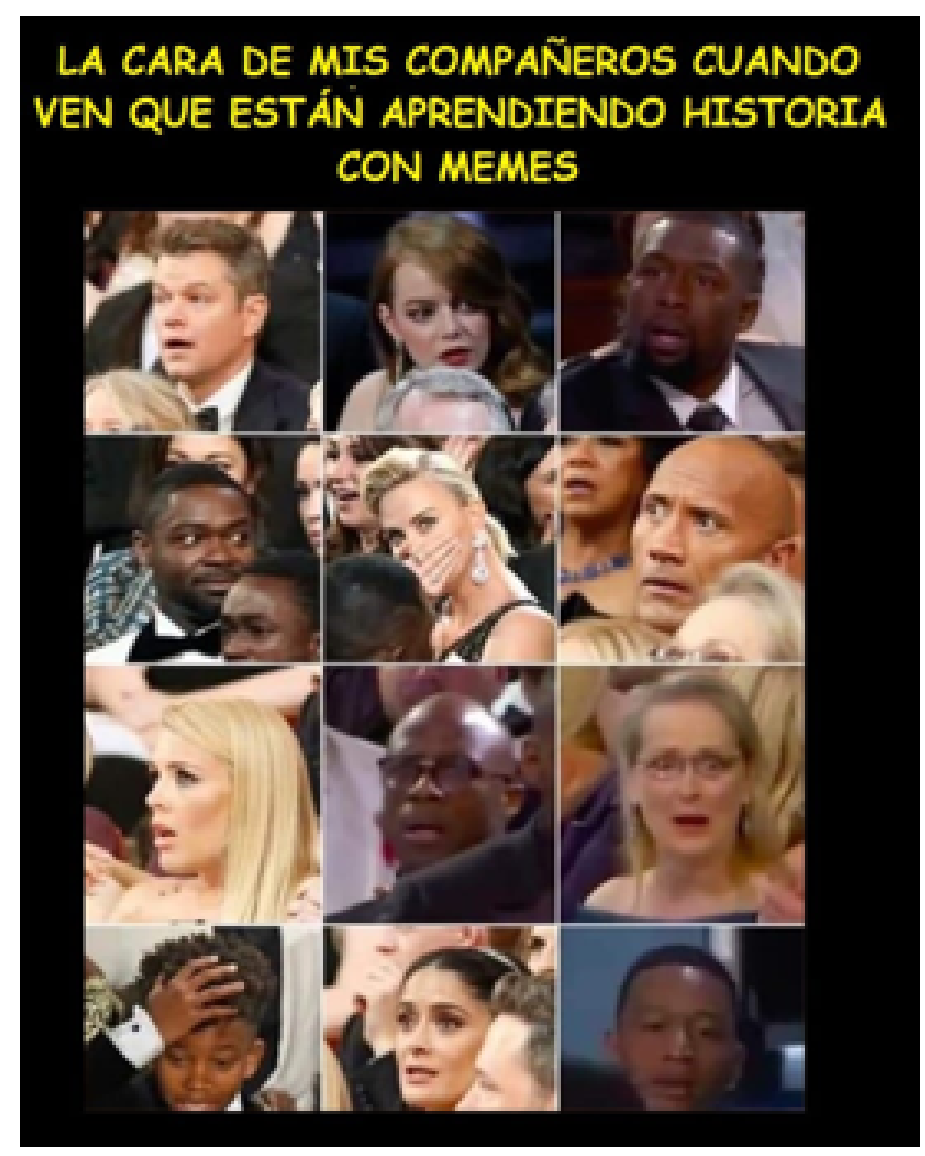

Fig. 10. Meme confeccionado por un alumno/a en el desarrollo de la actividad.

\section{CONCLUSIONES}

Tras la finalización de la experiencia didáctica, recogida la información del cuestionario y de la reflexión de los resultados podemos afirmar que el alumnado ha recibido esta práctica muy positivamente. Han entendido que el aprendizaje de la historia local les ha otorgado unos conocimientos válidos para su futura labor como docentes en Educación Primaria. A este respecto, la confección de los memes sobre los personajes históricos de Córdoba les ha motivado a investigar y seleccionar información del pasado, aplicando el razonamiento histórico, lo que han sido los pasos previos a la elaboración y difusión de su creación entre el resto de los compañeros y compañeras de clase a través de Facebook. Por eso mismo, se ha mostrado que la elaboración y difusión de memes puede ser válido como una herramienta para el aprendizaje de contenidos de carácter histórico, aunque en un primer momento pueda resultar extraño al estudiantado (véase fig. 10). Cada historia tiene su relato y el alumnado ha entendido que es capaz, incluso con un lenguaje muy actual y aparentemente tan ajeno a la tradicional forma de contar la historia, de elaborar un relato sobre el pasado. Además, con la creación de memes, ha podido interesarse por la construcción del lenguaje temporal y su importancia en el desarrollo de los niños y las niñas en la etapa de Primaria. 
Con todo, en ambos aspectos se dieron unos primeros pasos y entendemos que se hace necesario continuar en esta línea para obtener resultados mucho más concretos.

Igualmente, se comprobó un aumento de la motivación del profesorado en formación por los contenidos de carácter histórico, incentivando su curiosidad e interés por aprender. Por una parte, el manejo de las TIC ha reforzado la práctica educativa propuesta, ya que para nuestro estudiantado ha resultado mucho más fácil el aprendizaje utilizando un lenguaje más cercano a ellos, en vez del estrictamente académico y es por ello que hemos comprobado que un aprendizaje lúdico no está en contraposición de la adquisición de contenidos de naturaleza más teórica.

En definitiva, parece que estas son las directrices que deben tener en cuenta para formar a los próximos maestros: facultándoles los utensilios necesarios para que sean capaces de pensar y construir críticamente la Historia, a la vez que se utilizan recursos TIC como herramientas de análisis y de incentivación al aprendizaje.

\section{REFERENCIAS}

AKTEKIN, S. (2010). The place and importance of Local History in the Secondary History Education. En Eğitimde Kuram ve Uygulama-Journal of Theory and Practice in Education, 6 (1), 86-105.

ARANGO, L. (2014). Experiencias en el uso de los memes como estrategia didáctica en el aula. En Congreso Iberoamericano de Ciencia, Tecnología, Innovación y Educación (en línea). Recuperado de www.oei.es/historico/congreso2014/memoriactei/1513.pdf

ARANGO, L. (2015). Una aproximación al fenómeno de los memes en Internet: claves para su comprensión y su posible integración pedagógica. En Comunicação Mídia e Consumo, 12 (33), 110-132.

BELTRÁN, P. (2016). Utilizando memes con tus alumnos. En Números. Revista de Didáctica de las Matemáticas. Vol. 91, marzo, 129-134.

BLACKMORE, S. (2000). The meme machine. Oxford University Press.

CLIO '92 (1995). Tesi sulla didattica della storia, Per la conoscenza delle storie locali nella scuola, Tesi sul curricoli della scuola elementare, Quaderno 1, aprile 2000, ora in www.storiairreer.it.

DAWKINS (1976). The selfish gene. Oxford University Press.

DENISOVA, A. (2019). Internet Memes and Society: Social, Cultural, and Political Contexts. Routledge

DOMÍNGUEZ, J. (2015). Pensamiento histórico y evaluación de competencias. Barcelona: Graó. 
DOMínGUEZ, J. (1986). La historia local en la escuela. En Domínguez, J. Vidaechea, T. (Coords.) El entorno en las Ciencias Sociales. Segovia: Secretaría General Técnica. Centro de Publicaciones. Ministerio de Educación y Ciencia, 63-74.

GÓMEZ, C. J.; MIRALLES, P.; LÓPEZ, R. y PRATS, J. (2017). Las competencias históricas en el horizonte. Propuestas presentes y perspectivas de futuro. En López, R.; MIRALLES, P. y PRATS, J. (Ed.). Enseñanza de la historia y competencias educativas. Barcelona: Graó, 2015-227.

GRUNDLINGH, L. (2017). Memes as speech acts. Social Semiotics, 28 (2), pp. 147-168 (en línea). Recuperado de http://dx.doi.org/10.1080/10350 330.2017.1303020.

GUTIÉRREZ, A. y TYNER, K. (2012). Educación para los medios, alfabetización mediática y competencia digital. En Comunicar, Revista Científica de Educomunicación, Vol. XIX (38), pp. 31-39.

HERRERA, H. H. (2012), Las redes sociales: una nueva herramienta de difusión. En $R e-$ flexiones, 91 (2), 121-128. Recuperado de http://www.redalyc.org/pdf/ 729/72923 962 008.pdf

HUNTINGTON, H. E. (2016). Pepper spray cop and the American dream: Using synecdoche and metaphor to unlock Internet memes' visual political rhetoric. En Communication Studies, 67(1), 77-93.

NISSENBAUM, A. y SHIFMAN, L. (2017). Internet memes as contested cultural capital: The case of 4chan's/b/board. En New Media \& Society, 19(4), 483-501.

PEDREÑO, D. (2015). Aportaciones Didácticas de la Historia Local y Familiar al Proceso de Enseñanza-Aprendizaje de las Ciencias Sociales. Experiencias en Tres Centros Educativos de la Región de Murcia de Educación Primaria, Secundaria y PCPI. Tesis defendida en la Universidad de Murcia. URI: http://hdl.handle.net/10 201/46981.

PÉREZ, G. (2017). El meme en Internet. Identidad y usos sociales. Fontamara, Universidad Autónoma de Coahuila.

PRATS, J. (1996). El estudio de la Historia local como opción didáctica. ¿destruir o explicar la historia. En Íber Didáctica de las ciencias sociales, geografía. e historia, 8, 93106.

PRENDES, M. (2007). Internet aplicado a la educación: estrategias didácticas y metodologías. En Cabero, J. (coord.). Nuevas tecnologías aplicadas a la Educación. España: McGraw-Hill, 205-222.

ROGERS, A. (1972). Approaches to Local History. London-New York: Ed. Longman.

ROSS, A. S. y RIVERS, D. J. (2017). Digital cultures of political participation: Internet memes and the discursive delegitimization of the 2016 US Presidential candidates. En Discourse, Context y Media, 16, 1-11. 
SÁIZ, J. y GÓMEZ, C. J. (2016). Investigar el pensamiento histórico y narrativo en la formación del profesorado: fundamentos teóricos y metodológicos. En Revista electrónica interuniversitaria de formación de profesorado, 19 (1), 175-190.

SANTISTEBAN, A. (2010). La formación de competencias de pensamiento histórico. En Clio \& asociados: La historia enseñada, 14, 34-56.

SCARDINA, C. (2017). Through the Lens of Popular Culture. Why memes and Teaching Are Well Suited. En Teacher Librarian, 45 (2), 13-16.

SEIXAS, P. (2013). Linking Historical Thinking Concepts, Content and Competencies. National Meeting of The Historical Thinking Project. Toronto: University of British Columbia.

SEIXAS, P. y MORTON, T. (2013). The Big Six Historical Thinking Concepts. Toronto: Nelson Education.

VÉLEZ, J. I. (2013). Memética como herramienta científica para el estudio de los memes de Internet [Tesis de doctorado]. Instituto Tecnológico y de Estudios Superiores de Monterrey.

VERA, E. B. (2019). Cuando el meme educa: la herramienta tecnológica del presente. En Viralizar la educación. Red de experiencias didácticas en torno al Meme de Internet. Ecuador: Esmeraldas, 38-55.

VERA, E. B. (2016). El meme como nexo entre el sistema educativo y el nativo digital: tres propuestas para la enseñanza de Lenguaje y Comunicación. En Revista Educación y Tecnología, (8). Vol. 2, 1-15.

ZEPEDA, R.E y EZQUERRA, N.B. (2011). Arte y oficio de enseñar. Dos siglos de perspectiva histórica. En XVI Coloquio Nacional de Historia de la Educación, El Burgo de Osma, Soria, 11-13 de julio de 2011, Vol. 1, 459-463. 